\title{
Chemistry Journal Use and Cost: Results of a Longitudinal Study
}

\author{
Tina E. Chrzastowski and Brian M. Olesko
}

\begin{abstract}
Journal-use studies were conducted in the University of Illinois at UrbanaChampaign Chemistry Library in 1988, 1993, and most recently in 1996. Between 1988 and 1996, the cost of purchasing the journal collection rose $66.9 \%$ while use of the collection rose $34.2 \%$. These increases occurred during the cancellation of over 180 chemistry journals between 1988 and 1996. The data point to a collection with obvious "top" journals that generate most of the use. While the data confirm the $80 / 20$ rule ( $84 \%$ of use was generated by the top 100 joumals in 1996, approximately 20\% of the journal collection), journal use is even more focused toward the top: approximately 40\% of all use in 1996 was generated by the top 10 titles. Use of the top 10 journals rose $60 \%$ between 1988 and 1996, with nearly identical titles occupying the top 10 positions over 8 years. Longitudinal trends in journal use and cost are explored, recommendations are made for successful journal-use study methodologies, and time series, data-centered collection development is addressed.
\end{abstract}

ournal-use studies were conducted in the University of Illinois at Urbana-Champaign (UIUC) Chemistry Library in 1988, 1993, and most recently in 1996 . The initial purpose for these surveys was grim: to determine use and cost-use ratio of a large and expensive serial collection in order to cancel subscriptions and balance the budget based on quantitative data. Although the original reasons for data collection were negative, the merits and multiple uses of these data have proved the efforts very worthwhile. These use surveys have provided data that have helped determine the effect of serial cancellations on the collection, whether the collection has sustained serious damage, or if it is still a vital and useful collection of chemistry serials.
Because chemistry serials are among the most expensive journals purchased by academic libraries, they are often targeted for cancellation. Use data and cost-use ratios can demonstrate how cost-effective a highuse chemistry serial collection can be. These kind of data also serve to provide factual, statistical reasons to give to faculty to explain why a serial was canceled or to library administrators to demonstrate why an expensive journal is cost-effective to own.

\section{Previous Research}

Although many types of periodical use studies have been published, only two have reported on local, longitudinal journal use. Parsons (1989) examined journal

Tina E. Chazastowski (CHRZ@uiuc.edu) is Chemistry Librarian and Associate Professor of Library Administration, University of Illinois at Urbana-Champaign; BRIAN M. Olesko (bolesko@discover.wright.edu) was formerly Graduate Assistant, UIUC Chemistry Library, and graduate student, UIUC Graduate School of Library and Information Science, and is now Reference and Outreach Librarian, Fordham Health Science Library, Wright State University. Manuscript received December 2, 1996; accepted for publication January 27, 1997. 
use of the botany serial collection at the John N. Couch Biology Library at University of North Carolina at Chapel Hill over a seven-year period, from 1982 to 1988. Parsons examined total use of botany titles over this time period in order to investigate cumulative data, but she limited her analysis to the general categories of used and unused titles. She did not track use by title, by year, as it changed over time.

Naylor (1994) examined periodical use through two use studies with differing methodologies conducted in 1987-88 and 1991-92 at the State University of New York at Buffalo Science and Engineering Library. Naylor focused on methodological differences between two studies. The first study used a reshelving methodology, while the later one used a self-reporting methodology. When all currently received serials were included in the study, an $18 \%$ drop in use occurred between the original study and the later one. Naylor concluded that the differences in reported use stem almost entirely from the methodologies employed, not from an actual change in usage patterns.

\section{METHODOLOGIES}

The same, simple methodology for measuring the use of journal subscriptions was employed in three separate use studies in the UIUC Chemistry Library in 1988, 1993, and 1996. A detailed description of the methodology is found in Chrzastowski (1991). Use was recorded by title (and by decade of publication in the 1993 and
1996 studies) as journals were reshelved, returned from interlibrary loan (ILL), or returned from a two-hour loan period. An alphabetical list of journals was kept to tally these uses manually. The 1988 study continued for six months, January through June. This length of survey was found to be unworkably long, and the 1993 and 1996 studies were conducted during three months, January through March. The data from 1993 and 1996 were doubled to compare the three studies. Both the six-month and the doubled three-month periods contain session breaks and a similar number of in-session weeks of class.

Each use study relied upon regular student staff to conduct and complete the data collection. No additional staff were hired to measure journal use. Student workers were asked to tally the number of journals they shelved in addition to their regular responsibilities, which include working at the circulation desk, shelving, shelf reading, and keeping the library orderly.

\section{Environmental Changes}

Very little environmental change took place during the eight years of the study periods. There was no dramatic rise in the number of students, staff, or faculty members. Fewer serials were purchased due to cancellations, and although the materials budget increased (see table 1), the increases were not sufficient to keep up with serial inflation. The changes that did occur in the physical location were more computer workstations, an increased

TABLE 1

OVERVIEW OF USE AND COST DATA FOR 1988, 1993, AND 1996 FOR THE UIUC CHEMISTRY LIBRARY

\begin{tabular}{lcccc}
\hline & 1988 & 1993 & 1996 & $\begin{array}{c}\% \text { Change } \\
\text { ('88 to '96) }\end{array}$ \\
\hline $\begin{array}{l}\text { Total materials } \\
\text { budget }\end{array}$ & $\$ 269,875.00$ & $\$ 357,922.00$ & $\$ 409,213.00$ & +51.6 \\
$\begin{array}{c}\text { Total spent on } \\
\text { journals }\end{array}$ & $\$ 223,823.18$ & $\$ 313,356.19$ & $\$ 373,698.98$ & +66.9 \\
$\begin{array}{c}\text { Percent of budget } \\
\text { spent on journals }\end{array}$ & $82.9 \%$ & $87.5 \%$ & $91.3 \%$ & +9.2 \\
$\begin{array}{c}\text { Total journal use } \\
6 \text { months }\end{array}$ & 31,501 & 46,824 & 42,266 & +34.2 \\
\hline
\end{tabular}


number of photocopiers of better quality, and the introduction of IBIS (Illinois Bibliographic Information Service) in 1991. IBIS is the UIUC locally loaded database of 27 journal indexes and includes all seven sections of Current Contents among others. The Physical Sciences section of Current Contents is the IBIS database which most directly serves chemistry-related research.

\section{HYPOTHESES}

A number of hypotheses were made concerning the studies' results. Many of these are based on the trends established in the 1988 and 1993 journal-use surveys. The hypotheses for this eight-year, longitudinal study are:

1. Total journal use will increase between 1988 and 1996 despite continued serial cancellations.

2. Off-campus interlibrary loan use (ILL) of the chemistry journal collection will grow based on other libraries' cancellations and the dependence on UIUC as a regional source for chemistry journals.

3. Journal use will increase over $30 \%$ in the top 100 journals (approximately the top $20 \%$ of the collection).

4. The percentage of total use of the journal collection will increase most in the top $1 \%-5 \%$ of the pyramid of journal titles, i.e., high use in the top 10 titles will beget higher use in the following years.

5. Journal use will increase and correlate positively with the use of the library's online journal indexes (IBIS) in the UIUC Chemistry Library.

\section{Results}

\section{TOTAL USE}

An overview of use and cost data for the three use studies is shown in table 1 . The cost of owning this expensive collection of science serials grew by $66.9 \%$ between 1988 and 1996, with the increased amount purchasing approximately 180 fewer titles in 1988 than in 1996. Although the materials budget for the Chemistry Library increased by
$51.6 \%$, it was not enough to continue to purchase the same number of journals. The serial collection has consumed the entire materials budget for chemistry, totaling $91.3 \%$ of the budget by 1996 (see table 1). In fact, after a successful 1991 Centennial Celebration Endowment campaign, all chemistry monographs are now purchased with donated funds or through the library's monograph approval plan, not with the Chemistry Library materials budget.

As predicted by the first hypothesis, use of the journal collection rose by a total of $34.2 \%$; this increase in use was easy to predict due to the trends found in previous use studies and through observation. Results from 1988 and 1993 were used to identify and cancel only those titles that were either unused, showed low use, or were not cost-effective to own (i.e., they had low use and high cost). However, canceling unused or low-use journals would not necessarily result in higher use of the journals to which the library still subscribed.

The increase in journal use might be attributable to the widely successful introduction of IBIS. A study of the effects of IBIS on journal use in the UIUC Chemistry Library was reported in 1995, and the author concluded that "patrons are finding valid, useful references to journal articles with less effort via IBIS" (Chrzastowski 1995, 641). Patrons have been able to generate lists of journal references more easily, giving them more time to locate and use journals.

Another interesting use figure is the $50 \%$ rise in journal use between 1988 and 1993 and later slight decline in use between 1993 and 1996 (see table 1). While the data show that journal use decreased in 1993 to 1996, and while the conclusions of this article are based on these data, observations of the library unit and other statistical measurements suggest that journal use increased. It is likely that once a high level of use is achieved, it becomes much more difficult to count all uses accurately using the methodology introduced in 1988 and repeated in 1993 and 1996. This problem is addressed later in this article. 
TABLE 2

1988, 1993 AND 1996 Use STUdy Results BY TyPE OF USE

\begin{tabular}{lrrr}
\hline & 1988 & 1993 & 1996 \\
\hline $\begin{array}{l}\text { In-library use } \\
\text { (from reshelving) }\end{array}$ & 28,367 & 45,632 & 41,178 \\
2-hour circulation & 1,689 & 476 & 276 \\
ILL lending & & & \\
(non-UIUC borrowers) & 1,445 & 716 & 812 \\
Subtotal & 31,501 & 46,824 & 42,266 \\
ILL borrowing & & & \\
(access not ownership) & 202 & 160 & 224 \\
Total use & 31,703 & 46,984 & 42,490 \\
\hline
\end{tabular}

Note: Data are for six months of use.

\section{USE BY TYPE}

In table 2, journal use by type of circulation is broken down. Four different types of use were measured: (1) in-library use determined through reshelving; (2) twohour circulation outside the library; (3) circulation to other libraries through ILL; and (4) ILL borrowing.

Because Chemistry Library journals do not circulate (except for a two-hour period), most use of the collection is made in the library, as shown in table 2. Because circulation statistics (online or manual) are often used to document use and generate reports, it is critical to collect use statistics that reflect the enormous activity taking place in the serial collection and that do not show up in the online catalog circulation statistics.

The option for two-hour circulation outside the library shows a dramatic decrease over the period studied (see table 2). This might be attributed to the installation of more and better-quality photocopiers within the library. It might also reflect the increased pressure on scholars to conduct more research in a shorter period of time; library users might find that two-hour circulation, done by hand with manual charge cards, simply takes too much time and effort. The decrease in two-hour circulation is better for all library users, because they are now more likely to find needed volumes on the shelves and not circulating.
The second fluctuation in table 2 is found in ILL lending. In 1991 (between the 1988 and 1993 studies), ILL at UIUC underwent a major change. Subsidized funding for lending by the state ceased, and fees were subsequently raised. The drop in lending between 1988 and 1993 perhaps reflects this policy and the funding loss. However, as predicted by the second hypothesis, lending increased again by 1996 . Although the UIUC Chemistry Library has canceled and cut back nearly $25 \%$ of its chemistry serial collection, it still holds approximately 500 active chemistry serial subscriptions, and it can still be seen as a regional supplier for chemistry serial literature. These data lend support to the second hypothesis, although more data over a longer time period will be needed to confirm this hypothesis completely.

ILL also fluctuated over the course of the studies, rising slightly overall, but dipping in 1993. The increase in borrowing that might be expected as serial cancellations are made has not yet taken place. This is most likely due to the careful collection analysis-involving use studies and faculty consultation-that resulted in the cancellation of low-use, peripheral titles. It is also likely that the pressures of chemical science research do not allow patrons to wait the average two weeks for ILL materials. Yet another reason for steady numbers of ILL borrowing over 
TABLE 3

Bound And Unbound Use for the Three Study Periods 1988, 1993, And 1996

\begin{tabular}{lcll}
\hline \hline & 1988 & \multicolumn{1}{c}{1993} & \multicolumn{1}{c}{1996} \\
\hline Bound use & $25,390(80.6 \%)$ & $35,706(76.3 \%)$ & $31,458(74.4 \%)$ \\
Unbound use & $6,111(19.4 \%)$ & $11,118(23.7 \%)$ & $13,076(25.6 \%)$ \\
Total & 31,501 & 46,824 & 42,266 \\
\hline
\end{tabular}

Note: Data are for six months of use. These statistics do not include ILL borrowing since those requests resulted in photocopied articles and do not relate to Chemistry Library use by binding status.

eight years might be the IBIS system, which has made it easier for patrons to find more citations and utilize those articles that are available in the library.

A title-by-title analysis of 1996 ILL requests was made to determine what patrons needed that was not owned (Bliss 1996). A total of 112 requests were made between January and March 1996-94 for journal articles and 18 for patents. Because patents are not available on campus, these were removed from the analysis; it has always been necessary at UIUC to borrow both U.S. and foreign patents. Of the 94 requests for journal articles, 72 $(76.6 \%)$ were from journals never owned by UIUC, while $22(23.4 \%)$ were for journals currently or formerly part of the collection. Of these 22 titles, $8(8.5 \%)$ were previously canceled, $13(13.8 \%)$ were out for binding or otherwise unavailable for copying, and $1(1.1 \%)$ title was a recent subscription for which the library lacked the early volumes.

By looking at the 72 requests for titles never owned at UIUC, single requests for a single article (64 requests) made up the majority of requests. Seven titles were requested two times, and one was requested three times. The title requested three times was owned by the Chemistry Library, but requests were for volumes earlier than the library's subscription. The low rate of ILL borrowing relative to overall use suggests that the collection satisfies well over $90 \%$ of user needs. In fact, interlibrary borrowing represents just .45\% of total uses during the 1996 study.

However, there are ways that scholars can access needed information that bypass the library. For example, library users can use full-text electronic journals, com- mercial document delivery, or colleagueto-colleague article loans. It is possible these other avenues were pursued by UIUC chemistry researchers during the periods studied. Tracking this type of access was beyond the scope of this study.

\section{USE OF BOUND VERSUS \\ UNBOUND MATERIALS}

The ratio of use of bound to unbound materials noticeably increased in favor of unbound materials from 1988 to 1996 (see table 3 ). All UIUC Chemistry Library journals are bound, and most journal issues more than one year old are bound. Intuitively, use of bound materials should increase over time, as the number of bound volumes grows as a collection ages. Even with cancellations, the number of bound and unbound volumes maintains the same equilibrium (i.e., the number of bound volumes grows while the number of unbound volumes stays the same or even decreases due to cancellations). The steady increase in the number of uses of unbound versus bound materials points to the growing immediacy of the chemistry serial collection. Chemistry is a discipline almost totally dependent on serial literature; it is imperative to stay current, and researchers stay current by reading the most recent, and therefore unbound, serials.

\section{USE OF THE “TOP” JOURNALS}

Trueswell's 80/20 rule has been a determining model of collection use since first published (Trueswell 1969). Based on the UIUC Chemistry Library's journal collection of approximately 500 paid serial titles, the $80 / 20$ rule would measure use of the 
TABLE 4

Data FOR THE Top 100, Top 50, AND ToP 10 Journals For 1988, 1993, AND 1996

\begin{tabular}{lcccc}
\hline & 1988 & 1993 & 1996 & $\begin{array}{c}\% \text { Change } \\
\text { ('88 to '96) }\end{array}$ \\
\hline Top 100 Journals & & & & \\
Cost (annual) & $\$ 73,525.05$ & $\$ 126,215.90$ & $\$ 174,430.15$ & +137 \\
Use (6 months) & 25,147 & 38,737 & 35,578 & +41 \\
Cost-use ratio & $\$ 1.46$ & $\$ 1.62$ & $\$ 2.45$ & +67 \\
Percentage of total use & $80.7 \%$ & $82.7 \%$ & $84 \%$ & +4 \\
Top 50 Journals & & & & \\
Cost (annual) & $\$ 42,525.20$ & $\$ 76,186.21$ & $\$ 88,783.00$ & +109 \\
Use (6 months) & 20,504 & 32,779 & 29,614 & +44 \\
Cost-use ratio & $\$ 1.03$ & $\$ 1.16$ & $\$ 1.49$ & +44 \\
Percentage of total use & $65.8 \%$ & $70.0 \%$ & $70.0 \%$ & +6 \\
Top 10 Journals & & & & \\
Cost (annual) & $\$ 9,467.25$ & $\$ 16,998.00$ & $\$ 24,541.00$ & +159 \\
Use (6 months) & 10,260 & 17,776 & 16,468 & +60 \\
Cost-use ratio & $\$ .46$ & $\$ .48$ & $\$ .74$ & +60 \\
Percentage of total use & $32.9 \%$ & $37.9 \%$ & $38.9 \%$ & +18 \\
\hline
\end{tabular}

"The "Cost-use ratio" is the number of annual journal uses divided into that year's annual subscription price. It has not been adjusted for the number of issues available per title, and therefore cannot be accurately labeled as "cost per use."

top 100 journals to verify Trueswell's rule. In fact, in $1996,84 \%$ of the use came from these top 100 journals, just slightly over Trueswell's prediction (see table 4). Use of the top 100 journals increased $41 \%$ between 1988 and 1996, addressing the third hypothesis, which predicted an increase of $30 \%$ in the top $20 \%$ of the journal collection. Use of the top journals was therefore higher than predicted.

It is possible that Trueswell's rule does not go quite far enough and was proposed at a time when financial constraints weren't so extreme. The data point to an extremely cost-effective top 10 titles that account for $38.9 \%$ of use by 1996 , climbing $60 \%$ from the previous 8 years (see table 4). Only 2 titles fluctuate out of the top 10 over the eight years, falling 2 places to numbers 11 and 12 ; these were replaced by journals previously in the top 15. In $1996,2 \%$ of total UIUC Chemistry Library journals (10 titles) accounted for nearly $40 \%$ of journal use, which might be considered a " $40 / 2$ " equation.
Garfield (1996) studied citation concentrations, which can be used to confirm that this phenomenon does not occur only in the UIUC Chemistry Library. In a study of 3,400 journals indexed by Science Citation Index in 1994 and reported in the Journal Citation Reports, Garfield found that $40 \%$ of citations (i.e., use) were generated by 100 journals, $2.9 \%$ of total journals indexed, a " $40 / 2.9$ " equation, similar to the findings of this study.

Table 4 shows the percentage of total use for the top 100, top 50, and top 10 titles. Although it is proposed that journal use was underrepresented by tallies in 1996, it is valid to look at the percentage of total tallied use for each year that each portion of the collection generated. The percentage of total use of the top 100 journals increased $4 \%$, the percentage of total use of the top 50 increased $6 \%$, while the percentage of total use of the top 10 titles increased $18 \%$ in eight years. It is obvious that the area of greatest concentration of use lies in the top 10 journals, which represent the top $2 \%$ of 
TABLE 5

Reshelving, Photocopying, IBIS, AND Journal-Use Statistics For the UIUC CHEMISTRY LIBRARY, 1988, 1993, AND 1996

\begin{tabular}{lccc}
\hline & 1988 & 1993 & 1996 \\
\hline Journal use & 31,501 & 46,824 & 42,266 \\
Journal reshelving & 31,594 & 48,470 & 41,798 \\
Photocopies made $^{*}$ & 141,479 & 329,409 & 369,500 \\
$\begin{array}{c}\text { IBIS connect hours } \\
\text { (hours:minutes:seconds) }\end{array}$ & $66: 36: 32^{\ddagger}$ & $388: 52: 04$ & $510: 34: 54$ \\
\hline
\end{tabular}

Note: All statistics have been corrected for a comparable 6-month period, January to June.

"In 1988 and 1993, three photocopiers were available; in 1996, 4 photocopiers were available. Copying could include notes and tests, but the vast majority of copying in the Chemistry Library is attributable to journal article photocopying.

${ }^{\dagger}$ IBIS connect hours were generated by Barbara Larson of AISS. Connect hours were measured at the UIUC Chemistry Library workstations only: 2 workstations in 1988, 3 in 1993, and 4 in 1996. Statistics are for connect hours to all Current Contents databases combined; Current Contents is the most frequently used and most subject specific database for Chemistry found on IBIS.

ISince IBIS was not introduced until late 1991, these connect hours are for January-June 1992.

the serial collection, confirming hypothesis number four.

\section{COST OF THE “TOP” JOURNALS}

The annual cost of purchasing the top 10 titles rose $159 \%$ in 8 years, reflecting annual inflation rates approaching $20 \%$ per year (see table 4). In comparison, the total chemistry journal collection grew in annual cost $66.9 \%$ over the same period, averaging approximately $8.4 \%$ per year (see table 1), less than half the inflation rate of the top 10 journals.

The correlation between high use and high cost has been noted before. According to Dougherty and Barr $(1988,8)$ : "Every study we've done or seen indicates that high cost and high use are linked.... Publishers know what they are doing when they price their core journals." This established correlation is why the names of the top journals or the use ranking by title established by this study are not included in this article. Publishers realize that "top" titles are unlikely to be canceled and therefore might be pricing their premier titles at higher rates than lesser-used titles. It is also possible that high-use titles are safe ways for publishers to expand the publishing pool, creating larger volumes or more frequently published issues, in- creasing both the price and the number of pages published. It is not surprising that there is a correlation between high use and higher rates of inflation, as the marketplace drives many collection development decisions in libraries during times of serial inflation (Chrzastowski and Schmidt 1996; Cummings et al. 1992). Libraries are forced to balance their serial budgets while receiving minimal increases, which results in journal cancellations. This leads to a reduction in profits for publishers, who then raise prices on premier core journals.

\section{Total USE Revisited}

As stated earlier, the data show that while journal use increased overall between 1988 and 1996, it declined between 1993 and 1996. In contrast, IBIS use increased steadily over the entire set of studies. Consequently, hypothesis 5 , which predicted an increase in journal use correlating with IBIS use, must be rejected (see table 5). Although journal use did increase overall (1988 to 1996), it does not follow the same even increases found in IBIS or photocopy statistics.

However, both direct observation in the library and data taken from outside the use study show that use of Chemistry 
Library collections and services consistently increased. Table 5 shows data from four separate and independent sources: (1) daily journal use tallied by student workers for the three use studies; (2) daily journal reshelving, tallied by all shelvers (staff and students); (3) number of photocopies made, tallied by counters attached to each copier; and (4) use of online journal indexes in the Chemistry Library based on transaction logs. The nonhuman tabulated elements-photocopier counters and online connect hours-closely match the observed use of the collection, which shows steady increases.

Photocopier counters provide the most valid nonhuman tabulated measurement of journal use in the UIUC Chemistry Library. Brown (1956) found that the chemistry discipline had the highest journal citation rate in the sciences $(93.6 \%$ ); thus, presumably, demand for journals is very high. Direct observation of journal use in the library suggests that it continues to increase. For example, large numbers of journals (which users are asked not to reshelve) are consistently found next to photocopiers, reinforcing the statistics taken from photocopier counters.

Data in table 5 also point out the difficulty in reproducing this study. The $50 \%$ increase in use (1988 to 1993) translates into a $50 \%$ increase in the time and energy needed to conduct the study. In 1988, journal use and reshelving were nearly identical, which is expected (see table 5). By 1993 , as use rose by $50 \%$ over 1988 , use was possibly underreported because there is little correlation to reshelving statistics. By 1996, it is difficult to see the relationship between use and reshelving, which are two separate measures of the same function: journal use. Due to the disparity between the data and observations of use, a survey was launched to "study the study" to gain insights on the data collection process.

\section{Use STUdY SURVEY}

Each of the 14 students who participated in data collection for the 1996 journal-use study was given a follow-up questionnaire. Eleven questionnaires $(78.6 \%)$ were returned. One was discounted; 10 were tallied. Appendix A shows the results of the survey.

It is obvious that the study was not carried out as planned, as all (100\%) of the students who replied admitted that there were times they could not record all journal uses (see appendix $A$, question 1 ). The majority of students $(60 \%)$ felt that their priority was to shelve, not to shelve and conduct the use study (see table 6, question 2). According to this survey, students were able to tally journal use approximately $84 \%$ of the time.

In question 5 , in which students were asked to identify the purpose of the study, it was found that the students did believe that both money and space savings were part of the objective. Only $10 \%$ of the students really hit the nail on the head: that the original purpose was simply to study journal use. It is often the case that other objectives become apparent after the fact; an unplanned component of this study was to measure student motivation and the effectiveness of our methodology.

It is important to note that students were initially trained to conduct the study. They were also told why the study was important and what the objectives were. Twothirds of the way through the study, the level of complaints by student workers grew fairly loud. Food was brought in to express thanks and appreciation for a job nearly completed. The edible encouragement did slightly improve morale and made it possible to complete the study. Thanks and food were also part of our "The JournalUse Study Is Finished!" celebration.

The most obvious conclusions are: first, that collection use has outgrown the methodology designed to study it, and second, there is only so much that student workers will and can be expected to do for minimum wage, especially when student employees in other units were not asked to perform the same duties.

\section{RECOMMENDATIONS FOR JOURNAL-USE STUDIES}

A number of recommendations for journal-use studies can be made based on this longitudinal use study. 
Barcoding of a collection is critical to enable a more precise and easier-toachieve use study. Students seem much more likely to whip out a scanner and "shoot" barcodes than to tally by hand on multiple sheets of paper, especially when they face long study periods or tens of thousands of tally marks. The Chemistry Library collection was barcoded in summer 1996, six months after the 1996 journal-use study was completed.

The purpose of the study should be clearly identified and reiterated throughout the study to those assigned the task of conducting the survey. Training, communicating goals, and following up during the study will secure more confident results. The study should be followed with a survey of participants to check on their perceptions. Those involved are able to provide the best feedback on methodology and give good recommendations for improvements. As Herzog $(1989,90)$ recommends for effective journal-use studies: "[T]est and revise, retest, and revise again."

Collect and tabulate data on every measurable library service. Correlations can be drawn between interconnecting services like photocopies and journal use, budget cuts and interlibrary borrowing, or library hours, journal use, and workstation transaction logs. Each library cause and effect will be reflected in the statistical record. Computerize the record to facilitate comparisons.

One snapshot of use or circulation data is useful and informative; it will begin to identify the collection's core and establish the pyramid of use: top, middle, and low-use journals. However, begin with a methodology and time period that will be easy to repeat. Even greatervalue comes from multiple studies over time, which document how the collection grows and changes.

\section{OTHER APPLICATIONS FOR Longtrudinal Journal-USE Data}

One of the most beneficial results of these use-by-title data is to manipulate the data for true collection development evaluation. Carrigan (1996a, 1996b) calls for an evaluation of collection development to determine both overselection (materials purchased and not used) and underselection (materials needed and not purchased). To evaluate collection development, rather than collections, use data is required. Hamaker (1995) rightly states that the greatest benefit to this type of collection evaluation is not just use data, but longitudinal use data ("circulation data" to Hamaker).

The longitudinal use data from this study point to a chemistry serial collection that has already benefited from this type of analysis. Beginning in 1988, all serial cancellations were made from the bottom of a list ordered from most cost-effective to least cost-effective. Cost-effectiveness was determined by a formula that estimated a cost-use ratio. In 1988, there still were journals being purchased that garnered zero use. These were the easiest to cancel. As time passed and budgets lost more purchasing power, the cost-use ratio grew to include titles with documented (albeit still low) use. The studies were repeated over the years because of the important role of current data in determining cost-effectiveness, and the political benefit of owning current, objective data.

By 1996, the defining line between journals to keep and those to cancel reached a cost-use ratio of $\$ 40.00$-what might be considered a very cost-effective journal to own in many university libraries. This ratio was chosen based on a science-journal document delivery cost. Many commercial document delivery companies charge in the $\$ 40$ range to copy and deliver an article. While it is easy to bemoan the loss of approximately 180 journals over the past eight years-nearly $25 \%$ of the serials collection in chemistrythe collection development evaluation made possible by the very use studies that determined the canceled titles now allows some satisfaction. Journal use is up (though fluctuating), the number of interlibrary loans remains stable and accounts for less than $1 \%$ of use, and there are no paid serial subscriptions that are not used. As accountability becomes a more critical factor in lean budget years, the question often becomes, "how effectively is the budget for materials being spent?" By collecting and analyzing longitudinal use or circulation data, either by title or by classifi- 
cation, this question can be addressed with confidence.

\section{Conclusions}

As mentioned earlier, collecting and analyzing longitudinal journal-use data have provided the answers to a number of collection evaluation questions. The data show a collection definitely under attack, with approximately $25 \%$ of the serial collection lost over eight years. However, serious damage to the usefulness and vitality of the collection has thus far been avoided due to careful dismantling and reliance on use and cost-effectiveness data from the studies. This is also a collection at its core, with a maximum cost-effectiveness level of $\$ 40.00$ per use establishing whether the library will continue to subscribe. There is no further room for canceling chemistry journals without seriously undermining the usefulness of the collection. The longitudinal data also establish that the methodology, which worked well in 1988, is not adequate for higher levels of use. Barcodes, applied in summer 1996, must be used to track and count uses in the next UIUC Chemistry Library joumal-use study, scheduled for January-March 1998.

The data from three use studies conducted over the past eight years point to the chemistry serials collection as a fluctuating, breathing force. In short, Ranganathan was right, a library is a growing organism. Use ebbs and flows, more or fewer ILL requests are made, journals used, and pages copied. The collection responds to movements in staff, numbers of copiers, hours of operation, seasons of the year, and most definitely to budgets, by breathing in and out. Literally a myriad of causes are marked by effects. The losses to the Chemistry Library serial collection can be measured in canceled serial titles, budgets that cannot keep pace with serial inflation, and in staff who cannot always be expected to incorporate new tasks, such as use studies, into their daily workflow. Fortunately, there are gains to balance these losses: a high use collection that is focused, balanced by interlibrary borrowing, able to continue to lend to others, and documented by the statistical record. The proof is in the inputting.

\section{Works CrTed}

Bliss, Vivian. 1996. User study: Chemistry library. [Unpublished report for LIS 450C.] Urbana, Ill.

Brown, Charles Harvey. 1956. Scientific serials. ACRL monograph no. 16. Chicago: ACRL.

Carrigan, Dennis P. 1996a. Data-guided collection development. College \& research libraries 57: 429-37.

Carrigan, Dennis P. 1996b. Collection development-evaluation. Journal of academic librarianship 22: 273-78.

Chrzastowski, Tina E. 1991. Journal collection cost-effectiveness in an academic chemistry library: Results of a cost/use survey at the University of Illinois at Urbana-Champaign. Collection management 14, no. 1/2: 85-98.

1995. Do workstations work too well?

An investigation into library workstation popularity and the "Principle of Least Effort." Joumal of the American Society for Information Science 46: 638-41.

Chrzastowski, Tina E., and Karen A. Schmidt. 1996. Collections at risk: Revisiting serial cancellations in academic libraries. College \& research libraries 57: 351-64.

Cummings, Anthony M., and others. 1992. University libraries and scholarly communication. Washington, D.C.: ARL for the Andrew W. Mellon Foundation.

Dougherty, Richard M., and Nancy E. Barr. 1988. Paying the piper: ARL libraries respond to skyrocketing journal subscription prices. Journal of academic librarianship 14: 4-9.

Garfield, Eugene. 1996. The significant scientific literature appears in a small core of journals. The scientist 10, no. 17 (Sept. 2): 13,16 . Available also from: http://165. 123.33.33/yr1996/sept/research_960902. html.

Hamaker, Chuck. 1995. Time-series circulation data for collection development or: You can't intuit that. Library acquisitions: practice \& theory 19: 191-95.

Herzog, Kate, and Harry Armistead. 1989. Designing effective journal use studies. The serials librarian 24, no. 3/4: 189-90.

Naylor, Maiken. 1994. Comparative results of two current periodical use studies. Library resources \& technical services 38: 373-88.

Parsons, Joan E. 1989. An analysis of the John N. Couch Biology Library-Botany section from 1982 through 1988. M.S. thesis, University of North Carolina at Chapel Hill.

Trueswell, Richard. 1969. Some behavioral patterns of library users: The $80 / 20$ rule. Wilson library bulletin 43: 458-61. 


\section{APPENDIX A \\ Journal-USe StUdy QUestionnarre Results FOR 1996}

1. Were there times when you were not able to record uses for all of the journals that you shelved?

$100 \%$ of respondents answered yes.

2. If you answered yes to question 1 , what would you say was a higher priority?

A. Making sure that all of the journals were shelved before your shift was over, even if this meant that you were unable to record all journal usage; or

B. Making sure that journal usage was recorded even if this meant that you would not be able to shelve all of the journals before the end of your shift.

$60 \%$ indicated that answer $A$ was a higher priority.

$20 \%$ indicated that answer $B$ was a higher priority.

$20 \%$ indicated that their priority was sometimes A and sometimes B.

3. Over the course of the study, what percentage of the journals that you shelved do you estimate you were able to record?

The average estimation of the percentage of journal use recorded $84.3 \%$.

The high and low estimations ranged from a high of $98 \%$ to a low of $10 \%$.

4. Was boredom or monotony a factor in your ability to record all journal usage?

Yes: $60 \%$

No: $40 \%$

5. As far as you know, what was the purpose of the use study? What did you think the data would be used for?

There were four different types of responses to this question.

Some provided more than one reason for doing the study.

The purpose of the study was:

To save money/cancel unused journals: $50 \%$

To save space/move unused journals: $40 \%$

To justify the cost of owned journals: $10 \%$

To see which journals were used: $10 \%$

6. Since you are the ones who performed the bulk of the data collection, do you feel that data collection procedures could be improved? How?

Responses to this question varied quite a bit. Some common themes include the idea of working in teams, barcoding, and making the tally sheets easier to use.

Note: Fourteen students particpated in the study; eleven questionnaires were returned (a 79\% return rate). 